\title{
Secular crustal deformation in central Japan, based on the wavelet analysis of GPS time-series data
}

\author{
K. Vijay Kumar ${ }^{1}$, Kaoru Miyashita ${ }^{1}$, and Jianxin $\mathrm{Li}^{2}$ \\ ${ }^{1}$ Graduate School of Science and Engineering, Ibaraki University, Mito 310-8512, Japan \\ ${ }^{2}$ DX Antenna Company Limited, Tokyo 160-0022, Japan
}

(Received July 30, 2001; Revised November 26, 2001; Accepted November 26, 2001)

\begin{abstract}
We adopted the wavelet technique to analyze the GPS time-series data of daily co-ordinates from the continuous GPS network, GEONET, during a four-year period (1996-1999). In the present analysis we removed the data jumps associated with earthquakes and due to artificial errors using ARMA technique, and also removed seasonal variations and white noises using the wavelet technique to estimate the secular crustal deformation in central Japan. The secular displacement vectors obtained were used to calculate various crustal strain fields in the study area by means of the least squares prediction technique. The secular displacement field was different from that estimated from the raw GPS time-series data, and we would have overestimated the secular strain components without considering them. The main characteristic features of the secular strain fields were as follows: (1) there existed a compressive regime in the entire region; (2) there was a remarkable peak around Tokyo Bay in the maximum shear strain distribution; (3) along the Shinanogawa seismic zone there existed a distinguishing boundary zone in the several kinds of strain fields.
\end{abstract}

\section{Introduction}

Central Japan is one of the most tectonically active areas of the Japan island-arc (Fig. 1), and its crustal activity is being monitored with great care. This region is characterised by mutual interactions of three or four plates, the Philippine Sea (PHS), the Pacific (PAC), the Eurasian (EUR) and the North American (NAM) plate (Yoshioka et al., 1993). Most recently, Heki et al. (1999) have proposed the microplate of the Amurian (AMR) plate, which is considered to be colliding with the northeast Japan arc in central Japan (Heki and Miyazaki, 2001; Miyazaki and Heki, 2001). The last major event in the Kanto region occurred along the Sagami trough (SaT in Fig. 1) and has been referred to as the 1923 Great Kanto Earthquake, which was a result of subduction of the PHS plate under the EUR or NAM plate (Kanamori, 1971; Ando, 1974; Ishibashi and Ishida, 1989). The postseismic crustal movement concerning this event has been studied by using seismological and geodetic data (Dambara and Hirobe, 1964; Scholz and Kato, 1978; Matsu'ura and Iwasaki, 1983). The Kanto region is considered to be in an interseismic period for the next Kanto earthquake, wherein the accumulation of tectonic stress is proceeding in the NAM-PHS plate boundary region (Yoshioka et al., 1994). The seismo-tectonics in the south Kanto and Tokai regions has been extensively studied referring to the major events, i.e., the 1923 Kanto, 1944 Tonankai and 1946 Nankaido earthquakes (e.g., Ando, 1974, 1975). The crustal deformation in this region has been investigated by Fujii and Nakane (1983), based on the conventional triangulation and trilatra-

Copy right(C) The Society of Geomagnetism and Earth, Planetary and Space Sciences (SGEPSS); The Seismological Society of Japan; The Volcanological Society of Japan; The Geodetic Society of Japan; The Japanese Society for Planetary Sciences. tion data from repeated surveys by the Japanese government survey teams. Recently, Sagiya (1999) and Mazzotti et al. (2001) have investigated the crustal deformation in central Japan using the GPS continuous data.

The Geographical Survey Institute of Japan (GSI) has introduced the GPS Earth Observation Network, GEONET, for continuous observation of the crustal deformation in the whole Japanese islands since 1994. Although continuous GPS observations of the crustal deformation by GSI were started in 1994, the observation sites of GEONET were increased in stages until 1999, when the network came into a full operation with about 1000 stations. The GPS site interval in the present study region (Fig. 1) is around $15 \sim 20$ km (Miyazaki and Hatanaka, 1997) and a daily precise position has been estimated for each of the sites. In this study we analyze the GPS time-series data in central Japan, and estimate the secular crustal displacement and strain fields to investigate the tectonics in and around central Japan.

The geodetic measurements, whichever are made on the surface or subsurface, are subjected to non-tectonic effects (Hudnut et al., 1996), and thus there arises the need to separate them from the tectonic signal. Although the space based geodetic techniques are cost-effective, they are influenced by several kinds of unwanted errors, among which the more serious ones are water vapor, multipath, mis-modeling due to antennae phase center variations. They may exaggerate the final outcome, namely, the secular crustal deformation. Here, we define the present secular deformation as a linear trend of the deformation without seasonal variations and abrupt discontinuities. Thus, we remove non-secular signals and noises from the GPS time-series data, based on the wavelet analysis, to estimate the secular crustal deformation field that could be used in our numerical investigation of the 


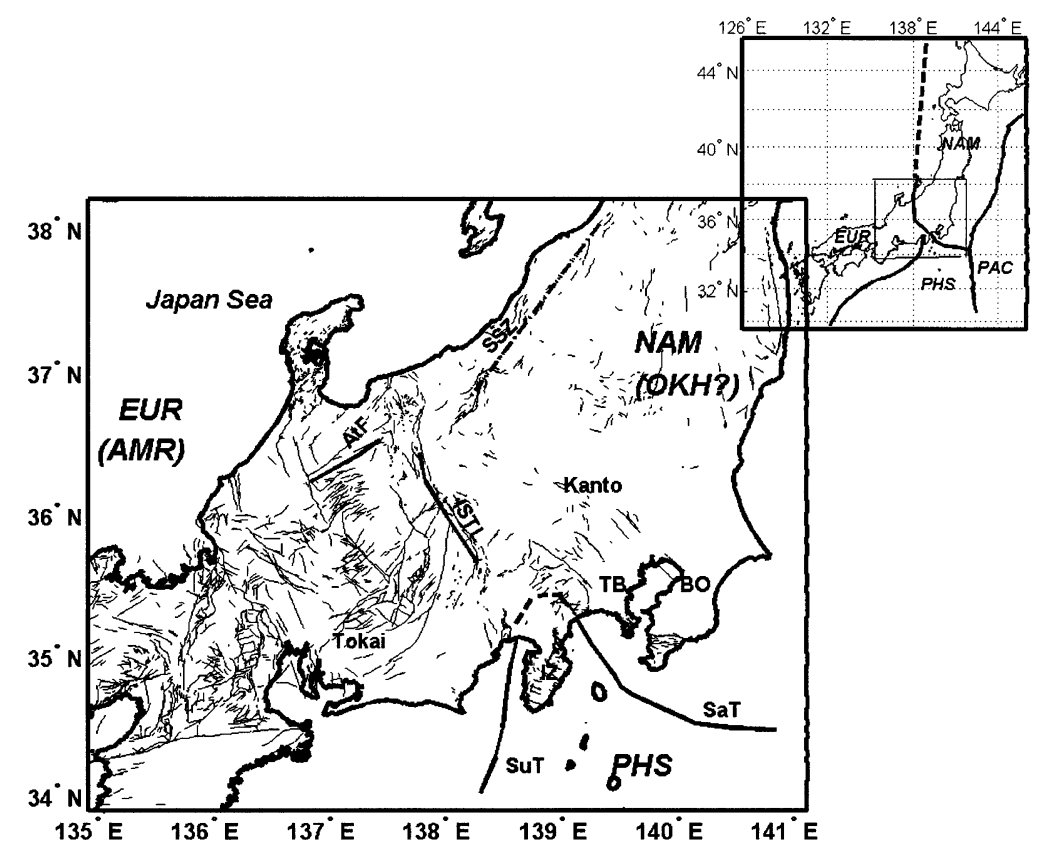

Fig. 1. Tectonic map of central Japan. NAM, PHS, PAC, EUR, AMR and OKH indicate North American, Philippine Sea, Pacific, Eurasian, Amurian and Okhotsk plates respectively. TB, BO, SaT, SuT, IZ, AtF and SSZ indicate Tokyo Bay, Boso peninsula, Sagami Trough, Surugua Trough, Izu peninsula, Atotsugawa fault and Shinanogawa seismic zone respectively. Active fault lines are shown in thin lines (Research group for active faults of Japan, 1991). The inset figure shows study region (inside box) along with the Japanese Islands. The plate boundaries are marked with thick lines and thick dotted lines represent speculated boundary.

seismo-tectonics in central Japan.

\section{Analysis of GPS Time-Series Data}

We used daily estimates of the positions of 340 sites in the $400 \times 400 \mathrm{~km}^{2}$ region (Fig. 1) for about four years (from 1996 to 1999), which have been estimated in the common reference frame of ITRF94 by GSI, Japan. The GPS data were analyzed at the GSI's processing centre, based on routine analysis strategy (Miyazaki et al., 1997), by using the Bernese software (Rothacher and Mervart, 1996) in combination with final orbits and earth rotation parameters of International GPS Service (IGS).

For obtaining raw time-series data, we transformed the changes in the position estimates of GPS sites in the ITRF94 coordinate system (i.e., $\mathrm{dX}, \mathrm{dY}$ and $\mathrm{dZ}$ ) to those in the local coordinate system (i.e., $\mathrm{dN}, \mathrm{dE}$ and $\mathrm{dU}$ ) by using the transformation routines available from the utilities of GAMIT software (King and Bock, 1998).

It has been clear from the earlier studies on GPS timeseries data (Li et al., 2000; Sagiya et al., 2000) that GPS stations move either linearly or periodically during a relatively short period if coseismic effects are removed. Hence, we assumed the time-series data were composed of secular (linear trend), seasonal and discontinuous (coseismic or artificial jumps) components with white noises. The discontinuities due to seismic events could be removed out by using the Auto Regressive Moving Average (ARMA) technique (Li et al., 2000). However, we adopted a little different approach by assuming that the coseismic and postseismic effects on the observations were present for a period of one week just after an earthquake occurrence. As there were no large earthquakes in the vicinity of our study region we ar- bitrarily considered one-week period, wherein the seismic effect due to small earthquake might have affected the data. Thus, we did not use the data for that period when there was a jump larger than $30 \mathrm{~mm}$ from the mean value in the ARMA approach. In order to smoothen the time-series data, which included jumps less than the limit, we also applied a Kalman filter to them following Li et al. (2000). After these procedures, we made the wavelet analysis for the corrected time-series data to remove their seasonal variations and white noises. We outline briefly the present wavelet analysis below.

\subsection{Wavelet analysis}

The wavelet techniques have been successfully applied to time-series data analyses, e.g., biometrical application (Percival, 1995), geophysical applications (Percival and Guttorp, 1994; Vecsey et al., 2001) and econometric application (Ruppert, 2001). The wavelets are often referred as "Mathematical Microscopes" as they reveal the finer details depending on the scale of operation (Vecsey et al., 2001).

We assumed the north-south (NS), east-west (EW) and up-down (UD) components of the GPS time-series data to be independent, and applied the wavelet tools of the Matlab software (Misiti et al., 1996). Although UD components were analyzed, we did not consider them in the present study as their accuracies were one order less than those of horizontal components. We observed that the seasonal effects on the GPS time-series data were more clearly visible on the UD component than on the EW and NS components.

\subsection{Decomposing and reconstructing time-series data}

We describe below the method of wavelet analysis to extract the information contained in the GPS time-series data. In this method, a time-series data $f(t)$ is expressed in terms 

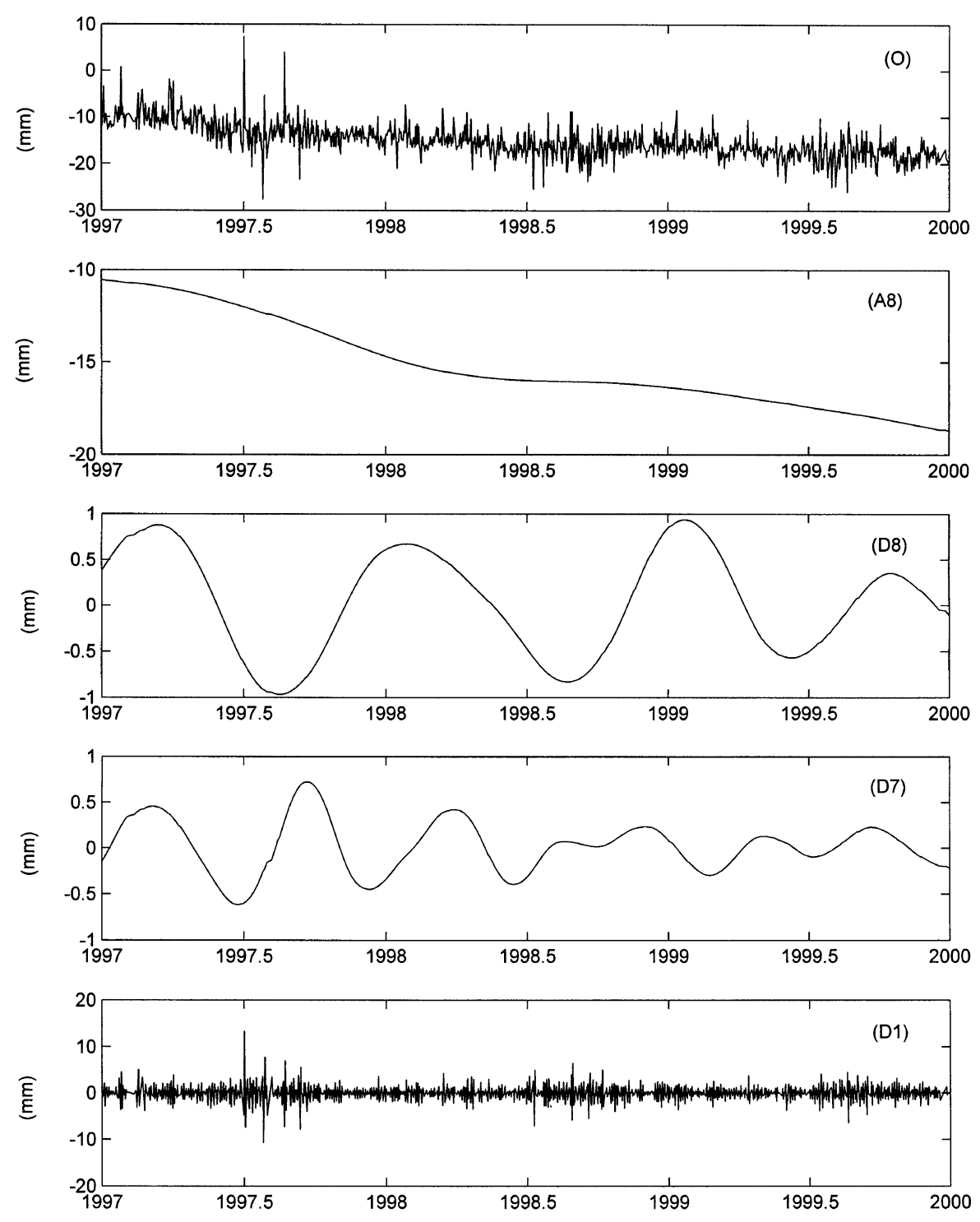

Time (Year)

Fig. 2. Result of the GPS time-series analysis with wavelet method as seen on east-west component of one of the site (950218). The original GPS time-series, the approximation component showing the linear trend at level 8 and the detail components at level 8, 7, 1 are indicated as O, A8, D8, D7 and D1 respectively.

of scaling and wavelet functions $\Phi(t)$ and $\Psi(t)$ as follows:

$$
f(t)=\sum_{k} c_{k}^{j 0} \Phi_{j 0, k}(t)+\sum_{j \geq j 0} \sum_{k} d_{k}^{j} \Psi_{j, k}(t)
$$

with

$$
\begin{aligned}
& \Phi_{j, k}(t)=2^{j / 2} \Phi\left(2^{j} t-k\right) \\
& \Psi_{j, k}(t)=2^{j / 2} \Psi\left(2^{j} t-k\right)
\end{aligned}
$$

where $j, k$ are known as the dilation and translate indices which respectively change the extent of the functions and their centered positions, and $c_{k}^{j}$ and $d_{k}^{j}$ are known as the approximate and detail coefficients.

The functions $\Phi(t)$ and $\Psi(t)$ are generated by taking a suitable linear combination of the box function $[\eta(t)=1$ for $0 \leq t \leq 1$, and 0 elsewhere]. For $\Phi(t)$ the coefficients are determined by the condition that the function is normalized, i.e., $\int \Phi(t) d t=1$ (Strang, 1989) and $\Psi(t)$ is similarly generated using the condition $\int \Psi(t) d t=0$.

The expansion coefficients $c_{k}^{j}$ and $d_{k}^{j}$ satisfy the following recurrence relations (Mallat, 1989),

$$
\begin{aligned}
& c_{k}^{j-1}=\sum_{i} h_{i-2 k} c_{i}^{j} \\
& d_{k}^{j-1}=\sum_{i} g_{i-2 k} c_{i}^{j}
\end{aligned}
$$

where $h$ and $g$ are called filter coefficients and form a low pass and a high pass filter, respectively. These relations give the expansion coefficients at one lower level $(j-1)$, in terms of the expansion coefficients at level $j$. The values of the filter coefficients are calculated from the coefficients of the scaling function itself (Misiti, 1996). At the highest 
level, $j=N$, where $N$ is the number of data points in the time-series, the expansion coefficients $c_{k}^{N}$ are chosen as the data point themselves, because at this level each data point is sampled separately. Using Eqs. (4) and (5) the expansion coefficients of Eq. (1) at a desired level are computed. Then, the original function $f(t)$ can be reconstructed at the desired level by "inverse transform." That is, the reconstructed function is composed of the approximate component at the desired level and all the detail components.

In this study, we applied the wavelet technique for removing the seasonal variations and white noises from the GPS time-series data. The characteristics of the white noise are as follows: 1) the amplitude of the detail component decreases as the level increases; 2) the variance of the detail component also decreases as the level increases. We used the basic wavelet family of the orthogonal Daubechie's family (Resnikoff et al., 1998; Misiti et al., 1996) as this could capture all the required details from the signal. We applied a certain criterion of level-dependent soft-thresholding to the detail component. After these procedures, the time-series data were reconstructed to be noise free.

In order to estimate the secular deformation from the GPS time-series data it is essential to remove the seasonal component from the data. We decomposed the GPS time-series data until the desired level of 8 , where we could capture the seasonal variation in the detail component. The linear trend of the approximation component at this level was considered to represent the secular deformation. As an example, we show the approximation and detail components of the EW component of a certain GPS time-series data in Fig. 2. From the approximation component at level 8 (A8 in the figure), we can estimate a linear trend, i.e., a secular displacement rate. The detail components at levels 8,7 and 1 are indicated in the lower three parts of the figure (D8, D7 and D1). The notable feature is that the detail component at level 8 (D8) has a seasonal variation with a period of about one-year. At lower levels the high frequency noises are detected as shown in the detail component at level 1 (D1).

The seasonal variations as well as the white noise components were filtered out from the GPS time-series data by using the above mentioned time-series analysis. The biggest advantage of this procedure is that it obviates the need of removing the noise by using specific regional averages as has been suggested by Mao et al. (1999) or by using other estimates (Dixon et al., 2000). We believe that the high frequency colored noise may also be getting filtered at the lower levels but it is likely that some of the low frequency colored noise still exists.

\subsection{Significance of present analysis}

The individual corrected GPS time-series data was considered to represent the secular component of crustal deformation at the GPS site. In order to check the improvement by the present analysis we reviewed the following three cases, namely, displacements at a particular GPS site, in a small region and in the whole study region. For the case of a particular GPS site (92108 in Izu Peninsula) we obtained a NS component of the secular displacement rate as $4.9 \mathrm{~mm} / \mathrm{yr}$, while the corresponding value of $16.9 \mathrm{~mm} / \mathrm{yr}$ was estimated from the raw GPS time-series data. This shows that the displacement rate obtained from the raw time- series data was overestimated, probably due to the high seismic activity around the GPS site. At some of the sites in the Chubu region showing relatively low seismic activity, the discrepancy was amounted to be about $20 \sim 30 \%$ that may be due to the effect of monumental instability or some local effects. Concerning average NS components of the displacement rates in certain small regions of south Kanto and Izu Peninsula including about 20 sites each, the discrepancies were found to be about $30 \%$ and $300 \%$ respectively. However, it was shown that for the entire study area the average EW and NS components of the displacement rate from the raw time-series data were $2 \%$ and $7 \%$ higher as compared to our estimates. The improvements on the GPS time-series data are clearly demonstrated in the displacement rate distribution in Fig. 3. Concerning the maximum shear strain rates estimated from the raw and improved GPS time series data, their discrepancy was substantially large in Izu Peninsula, where it was amounted to $0.14 \mathrm{microstrain} / \mathrm{yr}$.

\section{Secular Deformation Fields in Central Japan 3.1 Displacement field}

Figure 3 shows the horizontal displacement rates (red arrows), estimated from the genuine portion of the secular tectonic change in the GPS time-series data. Four year averaged secular displacements at GPS sites are represented along with those estimated from the raw time-series data (green arrows). We took Yasato as the reference site, where no monumental instability and very few seasonal effects were observed in the GPS time-series data. Recently most of the crustal deformation studies based on GPS data have used the displacement rates relative to some reference plate. For example, Miyazaki and Heki (2001) have fixed the kinematic reference frame to the AMR plate for estimating the velocity field in southwest Japan. Heki and Miyazaki (2001) and Mazzotti et al. (2001) have studied the long term displacements in central Japan by separating the short term displacement relative to one of the AMR, EUR and NAM plates.

The displacement field showed a dominant eastward movement in the northwestern part of the studied region and a westward movement along the northern and southern Pacific coast. The former was considered due to the motion of the EUR or AMR plate relative to the Okhotsk (OKH) or the NAM plate, and the latter because of the subduction of the PAC and PHS plates. These features were in good agreement with the results of Zhao (1999). The other prominent feature was observed in the Boso peninsula, where the NNW movements were clearly seen. Such a feature has been shown in the GPS analysis of the short time-interval data from the regional network (Vijaykumar and Miyashita, 2000). The distribution of displacements in and around the Izu peninsula was very complicated as expected from high seismic activities there. These effects could not be removed completely as some relevant postseismic effects could still be existing.

\subsection{Strain fields}

We applied the least square prediction method (e.g., Kato et al., 1998) to the displacement data for estimating continuous distributions of several strain components in the studied region. The strain fields were estimated at grid points of 


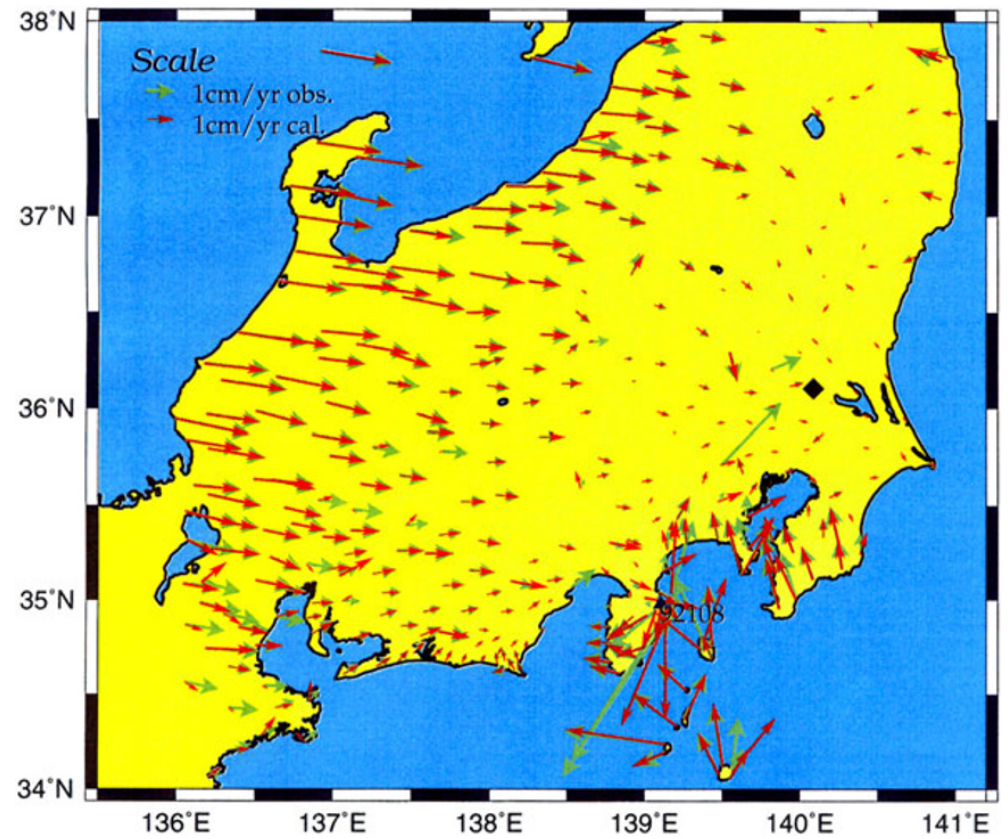

Fig. 3. Secular displacement rates at GPS sites in central Japan, estimated from GPS time-series data (April 1996 to December 1999) relative to Yasato. The black diamond indicates the fixed site of Yasato. Red arrows indicate the calculated displacement vectors from improved GPS time-series data, green arrows those from raw GPS time-series data.

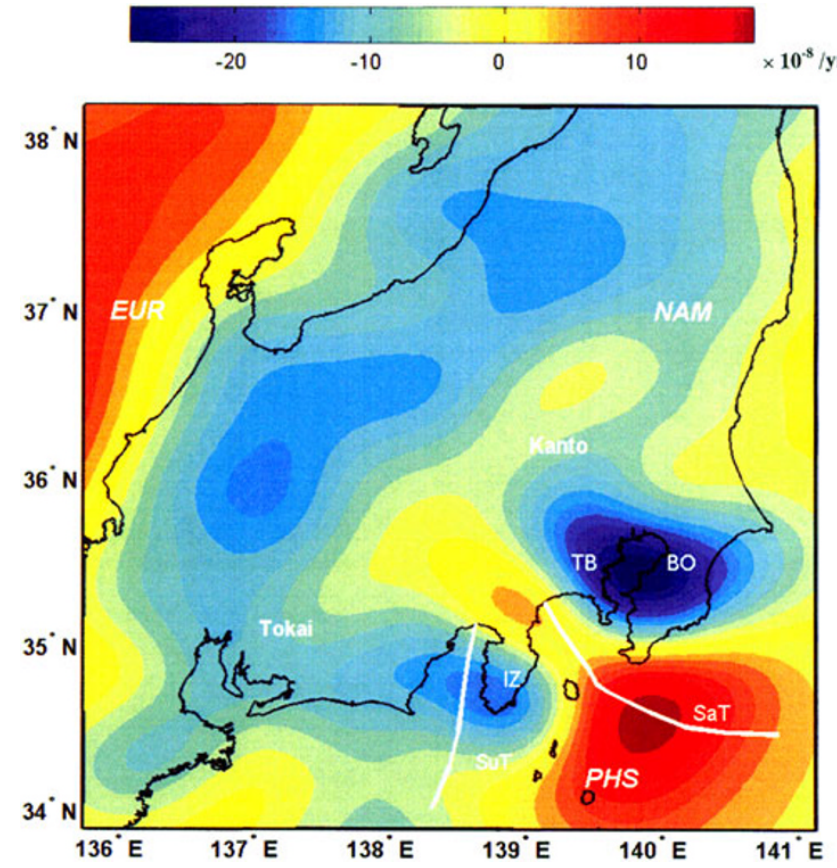

Fig. 4. Distribution of secular dilatational strain rates in central Japan for the period April 1996 to December 1999.

$7 \mathrm{~km} \times 7 \mathrm{~km}$ meshes covering central Japan.

In general the entire region showed a compressive regime (Fig. 4), as also shown in the earlier studies (e.g., Fujii and Nakane, 1983; Kato et al., 1998; Mazzotti et al., 2001). However, it was the most prominent feature in the dilatation field that there existed a highly compressed region near Tokyo Bay and the Boso peninsula. Such a high compression around Tokyo Bay could be mainly due to the effect of

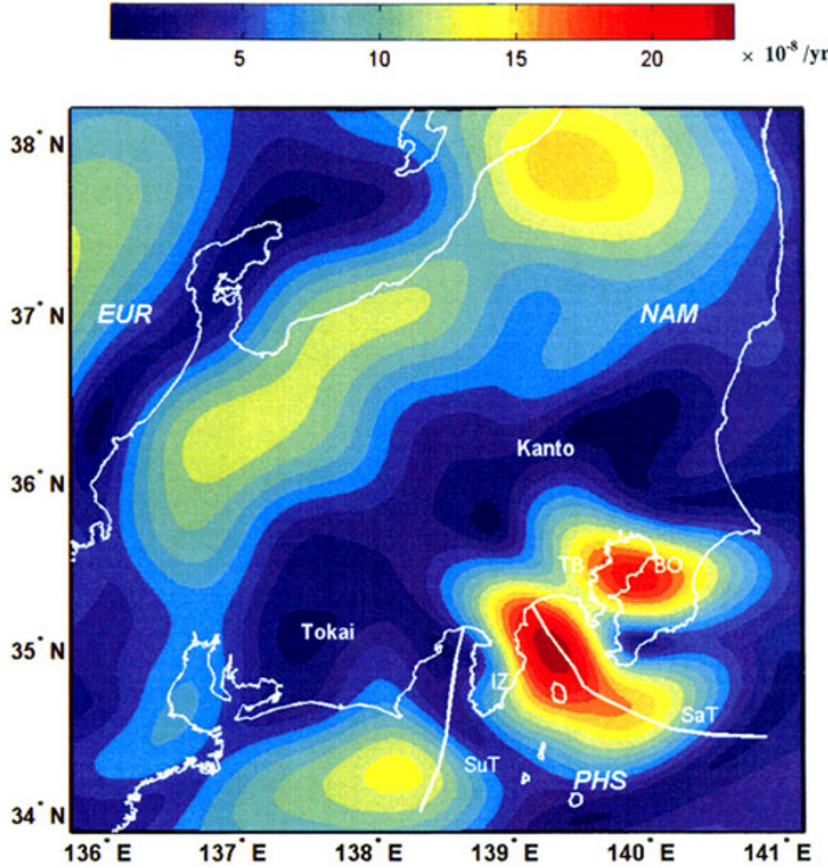

Fig. 5. Distribution of secular maximum shear strain rates in central Japan for the period April 1996 to December 1999.

the PHS plate subducting obliquely from the Sagami trough. A relatively high compression was also detected near the Izu peninsula, which might be due to the subduction and collision of the northern part of the PHS plate from the Suruga trough and at the northern end of the Izu peninsula respectively (Somerville, 1978; Sagiya, 1999; Mazzotti et al., 2001).

The distribution of maximum shear strain rates estimated 


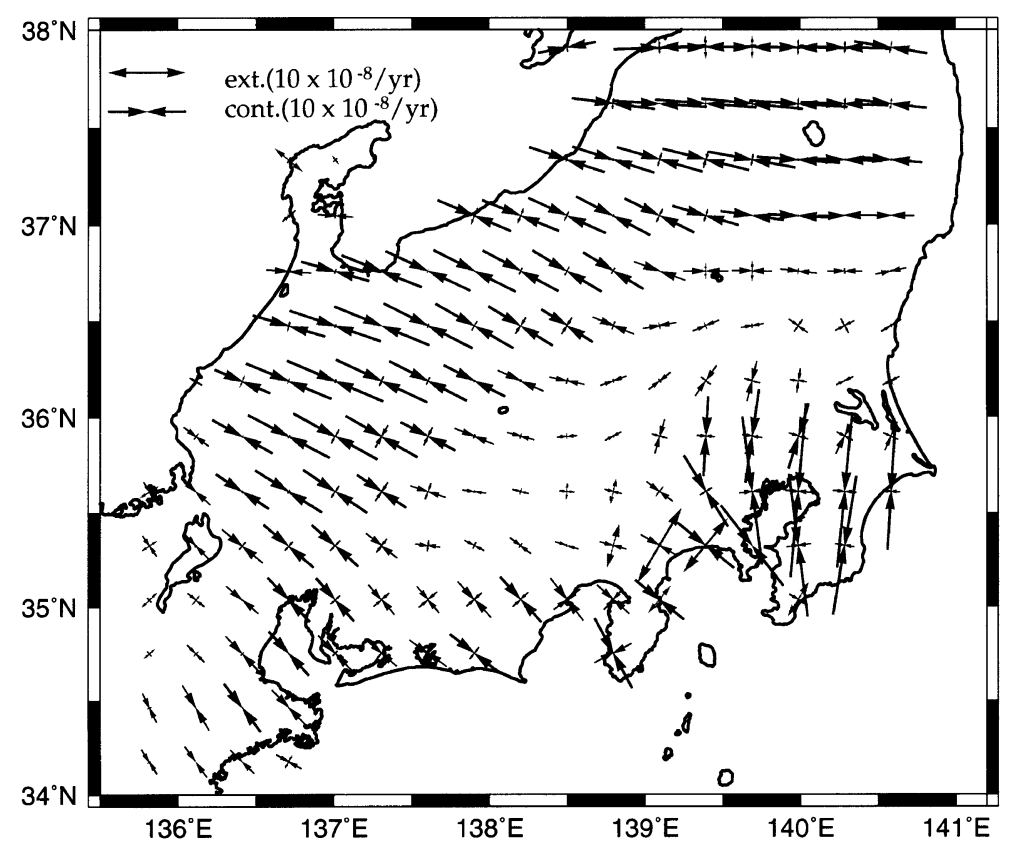

Fig. 6. Distribution of principal strain axes rates in central Japan for the period April 1996 to December 1999.

is shown in Fig. 5, where we can see distinguishing high strain patches near Tokyo Bay and Sagami Bay areas. The very high maximum shear strain patch located along the Sagami trough could be attributed to the contamination of the crustal deformations due to earthquake swarm activities around this region (October 1996, March 1997 and May 1998) according to Nishimura et al. (1998). The narrow zone of relatively high maximum shear strain rates close to the Japan Sea coast might correspond to the Shinanogawa seismic zone (SSZ in Fig. 1) and will be discussed later. On the contrary, the average maximum shear strain rate was found to be less than about $0.02 \mathrm{microstrain} / \mathrm{yr}$ in the inland regions of northern Kanto and northern Tokai, where no large seismic activities were observed.

Figure 6 indicates the distribution of principal strain axes, which clearly shows that the compressional strains (indicated by inward arrows) dominate over the extensional strains (outward arrows) in the entire region. Such a distribution coincides the results of Mazzotti et al. (2001) except their magnitudes. In general, the magnitudes of principal strains tend to increase from the eastern to western part of the whole region. The largest compression was observed in the Boso peninsula, which may be due to subduction of the PHS plate. The magnitudes of principal strains with an average of 0.12 microstrain/yr were three times larger than those from the triangulation data (Shen-Tu et al., 1995). The directions and magnitudes of the compressional principal strains were similar to those obtained with one-year GPS data by Kato et al. (1998).

\section{Discussion and Conclusion}

Applying the numerical techniques of ARMA and wavelet to analysis, we estimated the secular crustal deformation in central Japan from the GPS time-series data during April 1996 to December 1999. The characteristics of secular deformation seem to reflect the major tectonic environments in central Japan; (1) the dilatational strain distribution shows a clear existence of a compressive regime, (2) high maximum shear strain rates amounting to 0.12 microstrain/yr and 0.18 microstrain/yr, can be seen prominently around Sagami Bay and around Tokyo Bay and (3) the distributions of principal strain axes and displacement rates indicate an existence of a tectonic boundary along the Shinanogawa seismic zone and Atotsugawa fault (AtF in Fig. 1).

We obtained significant strain distributions whose trend shows a NE-SW direction across the Itoigawa-Shizuoka tectonic line (ISTL in Fig. 1). This corresponds to the Shinanogawa seismic zone and Atotsugawa fault zone. Sagiya et al. (2000) have considered this strain distribution corresponds to Niigata Kobe tectonic zone. It has been considered that most of the deformations in central Japan are accommodated along this zone (Hashimoto and Jackson, 1993; Hashimoto et al., 2000). Shimazaki and Zhao (2000) have considered a plate colliding boundary along this zone to explain the characteristic deformation estimated from GPS data. This has been classified as an active fault zone by the working group for compilation of active fault map based on the geographic features, geological formations and seismic activity observed in the past. Recently, Mazzotti et al. (2001) have reported that the high strains along Japanese Alps correspond to the eastern boundary of the AMR plate.

The patterns of the strain distributions are similar to those of the recent studies (e.g., Kato et al., 1998; Sagiya et al., 2000; Mazzotti et al., 2001). However, their magnitudes are different from those estimated earlier. The difference between maximum shear strain rate distributions from the raw and improved GPS time-series data was amounted to about 0.14 microstrain/yr in seismic active regions. This confirms the need of applying better numerical techniques such as the 
present wavelet analysis to the GPS time-series data in order to retrieve the secular crustal deformations.

Acknowledgments. The authors are grateful to Geographical Survey Institute, Japan for making available the four years of GPS data for this study. We would like to thank Dr. G. S. El-Fiky for allowing us to use his least square prediction software. We would also like to thank Dr. B. King, Dr. M. Tobita for giving us guidance in converting the positional coordinates to local coordinates. The valuable comments and careful reviews from Dr. S. Miyazaki and Dr. S. Mazzotti were extremely helpful in improving the manuscript.

\section{References}

Ando, M., Seismo-tectonics of the 1923 Kanto earthquake, J. Phys. Earth, 22, 263-227, 1974.

Ando, M., Possibility of a major earthquake in the Tokai district, Japan and its pre-estimated seismotectonic effects, Tectonophys., 25, 69-85, 1975.

Dambara, T. and M. Hirobe, Vertical movements of Japan during the past 60 years. II. Southern part of Kanto district, J. Geod. Soc. Japan, 10, 61-70, 1964 (in Japanese with English abstract).

Dixon, T. H., M. Miller, F. Farina, H. Wang, and D. Johnson, Present-day motion of the Sierra Nevada block and some tectonic implications for the Basin and Range province, North America Cordillera, Tectonics, 19, $1-24,2000$

Fujii, Y. and K. Nakane, Horizontal crustal movements in the Kanto-Tokai district, Japan, as deduced from geodetic data, Tectonophys., 97, 115$140,1983$.

Hashimoto, M. and D. D. Jackson, Plate tectonics and crustal deformation around the Japanese Islands, J. Geophys. Res., 98, 16149-16166, 1993.

Hashimoto, M., S. Miyazaki, and D. D. Jackson, A block-fault model for deformation of the Japanese Islands derived from continuous GPS observation, Earth Planets Space, 52, 1095-1100, 2000.

Heki, K. and S. Miyazaki, Plate convergence and long-term crustal deformation in central Japan, Geophys. Res. Lett., 28, 2313-2316, 2001.

Heki, K., S. Miyazaki, H. Takahashi, M. Kasahara, F. Kimata, S. Miura, N. F. Vasilenko, A. Ivashchenko, and K. An, The amurian plate motion and current plate kinematics in eastern Asia, J. Geophys. Res., 104, 29147 29155,1999

Hudnut, K. W., Z. Shen, M. Murray, S. Mclusky, R. King, T. Herring, B. Hager, Y. Feng, A. Donnellan, and Y. Bock, Co-seismic displacement of 1994 Northridge, California earthquake, Bull. Seis. Soc. Am., 86(13), 19-36, 1996.

Ishibashi, K. and M. Ishida, Seismic activity in the south Fossa Magna, Central Japan, Mod. Geol., 14, 19-33, 1989.

Kanamori, H., Faulting of the great Kanto earthquake of 1923 as revealed by seismological data, Bull. Earthq. Res. Inst. Univ. Tokyo, 49, 13-18, 1971.

Kato, T., G. S. El-Fiky, E. N. Oware, and S. Miyazaki, Crustal strains in the Japanese Islands as deduced from dense GPS array, Geophys. Res. Lett., 25, 3445-3448, 1998.

King, R. W. and Y. Bock, Documentation for GAMIT GPS analysis software, Massachusetts Institute of Technology, and University of California at San Diego, 1998

Li, J., K. Miyashita, T. Kato, and S. Miyazaki, GPS time series modeling by autoregressive moving average method: Application to the crustal deformation in central Japan, Earth Planets Space, 52, 155-162, 2000.

Mallat, S., A theory for multiresolution signal decomposition: the wavelet representation, IEEE Patern Anal. And Machine Intell., 11, 674-693, 1989.

Mao, A., C. G. A. Harrison, and T. H. Dixon, Noise in GPS coordinate time series, J. Geophys. Res., 104, 2797-2816, 1999.

Matsu'ura, M. and T. Iwasaki, Study on co-seismic and postseismic crustal movements associated with the 1923 Kanto earthquake, Tectonophys., 97, 201-215, 1983.

Mazzotti, S., P. Henry, X. L. Pichon, Transient and permanent deformation of central Japan estimated by GPS; 2. Strain partitioning and arc-arc collision, Earth Planet. Sci. Lett., 184, 455-469, 2001.

Misiti, M., Y. Misiti, G. Oppenheim, and J. M. Poggi, Wavelet tool box for use with Matlab, Natick, MA., 567 pp., The Math Works, Inc., 1996.

Miyazaki, S. and Y. Hatanaka, Crustal deformation observed by GSI's new GPS array, Eos Trans. AGU, 78, S104, 1997.

Miyazaki, S. and K. Heki, Crustal velocity field of southwest Japan: Subduction and arc-arc collision, J. Geophys. Res., 106, 4305-4326, 2001.

Miyazaki, S., T. Saito, M. Sasaki, Y. Hatanaka, and Y. Iimura, Expansion of GSI's nationwide GPS array, Bull. Geogr. Surv. Inst., 43, 22-34, 1997.

Nishimura, T., T. Sagiya, S. Odagiri, T. Tada, Crustal deformation associated with earthquake swarms at the Northeastern Izu peninsula, central Japan, and their dislocation models, Eos Trans. AGU, 79(45), Fall Meet. Suppl., F400, 1998.

Percival, D. B., On estimation of the wavelet variance, Biometrika, 82, 619631, 1995.

Percival, D. B. and P. Guttorp, Long-memory processes, the Allan variance and wavelets, in Wavelets in Geophysics, edited by E. F. OufoulaGeorgiou and P. Kumar, pp. 325-344, San Diego, Academic Press, 1994.

Research group for active faults in Japan, Maps of active faults in Japan with explanatory text, University of Tokyo Press, Hongo, Bunkyo-ku, Tokyo, 113, Japan, 1991.

Resnikoff, H. L. and R. O. Wells, Wavelet analysis, The scalable structure of information, 435 pp, Springer-Verlag, New-York, Inc., 1998.

Rothacher, M. and L. Mervart, Bernese GPS software version 4.0 Documentation, Astronomical Institute, University of Berne, 1996.

Ruppert, D., Univariate time series models, 2001 http://www.orie. cornell.edu/ davidr/or473/LectNotes/notes/ nodes $32 . \mathrm{html}$.

Sagiya, T., Interplate coupling in the Tokai district, central Japan, deduced from continuous GPS data, Geophys. Res. Lett., 26, 2315-2318, 1999.

Sagiya, T., S. Miyazaki, and T. Tada, Continuous GPS array and presentday crustal deformation of Japan, Pure Appl. Geophys., 157, 2303-2322, 2000.

Scholz, C. H. and T. Kato, The behavior of a convergent plate boundary: crustal deformation in the south Kanto district, Japan, J. Geophys. Res., 83, 783-797, 1978.

Shen-Tu, B., W. E. Holt, and A. J. Haines, Interplate deformations in the Japanese Island: A kinematic study of interplate deformation at a convergent plate margin, J. Geophys. Res., 100, 24275-24293, 1995.

Shimazaki, K. and Y. Zhao, Dislocation model for strain accumulation in a plate collision zone, Earth Planets Space, 52, 1091-1094, 2000.

Somerville, P., The accommodation of plate collision by deformationin the Izu block, Japan, Bull. Earthq. Res. Inst., 53, 629-648, 1978.

Strang, G., Wavelets and dilation equations: A brief introduction, Siam Review, 31, 613-627, 1989.

Vecsey, L., C. Hier, D. Yuen, and E. Sevre, Two dimensional wavelet analysis applied to geoid anomalies: Mixing and high Rayleigh number mantle convection, Electronic Geosciences, February 21, 2001.

Vijaykumar, K. and K. Miyashita, Regional network analysis of GPS data in the area of Kanto, central Japan, Earth Planet. Space Lett., 52, 971974, 2000.

Yoshioka, S., T. Yabuki, T. Sagiya, T. Tada, and M. Matsu'ura, Interplate coupling and relative plate motion in the Tokai district, central Japan, deduced from geodetic data inversion using ABIC, Geophys. J. Int., 113, 607-621, 1993.

Yoshioka, S., T. Yabuki, T. Sagiya, T. Tada, and M. Matsu'ura, Interplate coupling in the Kanto district, central Japan, deduced from geodetic data inversion and its tectonic implications, Tectonophys., 229, 181-200, 1994.

Zhao, Y., Application of dislocation model for plate collision to aseismic crustal deformation in central Japan, Ph.D. Thesis, University of Tokyo, 1999.

K. V. Kumar (e-mail: vijay@mcs.ipc.ibaraki.ac.jp), K. Miyashita, and J. Li 